\title{
New Surface Properties in Porcelain Gres Tiles with a Look to Human and Environmental Safety
}

\author{
C. L. Bianchi, ${ }^{1,2}$ C. Pirola, ${ }^{1,2}$ S. Gatto, ${ }^{1}$ S. Nucci, ${ }^{1}$ A. Minguzzi, ${ }^{1}$ G. Cerrato, ${ }^{2,3}$ \\ S. Biella, ${ }^{2,4}$ and V. Capucci ${ }^{5}$ \\ ${ }^{1}$ Dipartimento di Chimica, Università degli Studi di Milano, Via Golgi 19, 20133 Milan, Italy \\ ${ }^{2}$ Consorzio Interuniversitario Nazionale per la Scienza e Tecnologia dei Materiali, Via G. Giusti 9, 50121 Florence, Italy \\ ${ }^{3}$ Dipartimento di Chimica and NIS Centre of Excellence, Università degli Studi di Torino, Via P. Giuria 7, 10125 Turin, Italy \\ ${ }^{4}$ Dipartimento di Chimica, Materiali e Ingegneria Chimica “Giulio Natta”, Politecnico di Milano, Piazza Leonardo da Vinci 32, \\ 20133 Milan, Italy \\ ${ }^{5}$ GranitiFiandre S.p.A, Via Radici Nord 112, 42014 Castellarano, Italy
}

Correspondence should be addressed to C. L. Bianchi, claudia.bianchi@unimi.it

Received 23 February 2012; Accepted 16 July 2012

Academic Editor: Wilson Acchar

Copyright ( 2012 C. L. Bianchi et al. This is an open access article distributed under the Creative Commons Attribution License, which permits unrestricted use, distribution, and reproduction in any medium, provided the original work is properly cited.

\begin{abstract}
Traditional photocatalysis is here brought forward for both the use of nanosized $\mathrm{TiO}_{2}$ crystallites and the possibility to have a release of $\mathrm{TiO}_{2}$ particles during the final use of the manufactured products. In the present paper both the preparation and characterization of a new generation of photocatalytic tiles are presented. The originality of these products is the surface presence of microsized $\mathrm{TiO}_{2}$ as it is not clear yet the impact of the nanoparticles on both human and environmental safety. TiO ${ }_{2}$ is here mixed with a silica compound and the final thermal treatment at $680^{\circ} \mathrm{C}$ allows the complete surface vitrification which, in turn, makes the tiles surface strongly resistant to abrasion. Photocatalytic efficiency towards the degradation of $\mathrm{NO}_{x}$ in gas phase was measured in both a batch and a plug-flow reactor. The latter reactor configuration was also modeled by digital simulations.
\end{abstract}

\section{Introduction}

Porcelain gres tiles are characterized by a very low water absorption rate (less than $0.5 \%$ ) and are manufactured under high pressure by dry-pressing fine processed ceramic raw materials with large proportions of quartz, feldspar, and other fluxes. Afterwards, the body of these materials is fired at very high temperatures $\left(1200-1300^{\circ} \mathrm{C}\right)$ in kilns [1]. The final material is thus characterized by lack of porosity, complete water-proofing, durability, hardness, wear resistance properties, and a complete frost resistance.

In the past decades porcelain gres tiles underwent significant transformations in terms of appearance and size. At the beginning of the industrial productions, porcelain gres tiles were considered as just a technical material characterized by strong resistance to both abrasion and acid attack, almost lack of porosity, but aesthetically not very beautiful. Today thanks to new industrial production methods, both properties and beauty of these materials completely fit the market requests. In particular, the possibility to prepare slabs of large sizes is the new frontier of building materials.

Beside these noteworthy architectural features, new surface properties have been introduced in the last generation of these materials. The present paper reports the preparation and characterization at the base of a new kind of fired tiles able to reduce polluting molecules present in air thanks to its new photocatalytic properties. The extreme originality of these products is the surface presence of microsized $\mathrm{TiO}_{2}$. In fact it is not clear yet the impact of the possible release in the atmosphere of nanoparticles, in particular nano- $\mathrm{TiO}_{2}$, on both human and environmental safety.

Man-made nanostructured materials such as fullerenes, nanoparticles, nanopowders, nanotubes, nanowires, nanorods, nanofibers, quantum dots, dendrimers, nanoclusters, nanocrystals, and nanocomposites are globally produced in large quantities due to their wide potential applications, for 
example, in skincare and consumer products, healthcare, electronics, photonics, biotechnology, engineering products, pharmaceuticals, drug delivery, and agriculture. Human exposure to these nanostructured materials is inevitable, as they can enter the body through the lungs or other organs via food, drink, air, and medicine and affect different organs and tissues such as the brain, liver, kidney, heart, blood, and so forth and may cause cytotoxic effects, for example, deformation and inhibition of cell growth leading to various diseases in both humans and animals. Since a very wide variety of nanostructured materials exists, their interactions with biological systems and possible toxicity largely depend upon their properties, such as particle size, concentration, solubility, chemical and biological properties, and stability [2].

Titanium dioxide nanoparticles are manufactured worldwide in large quantities for use in a wide range of applications including pigment and cosmetic manufacturing. Although $\mathrm{TiO}_{2}$ is chemically inert, $\mathrm{TiO}_{2}$ nanoparticles can cause negative health effects, such as respiratory tract cancer in rats. Trouiller et al. [3] investigate $\mathrm{TiO}_{2}$ nanoparticles-induced genotoxicity, oxidative DNA damage, and inflammation in a mice model.

The possibility to use Microsized $\mathrm{TiO}_{2}$ in a commercial manufactured product opens a new generation of material intrinsically safer than the traditional photocatalytic products for both workers in the factories and public safety, even though, with such materials that are surface vitrified, the release of $\mathrm{TiO}_{2}$ particles is extremely remote.

In the present paper both preparation and characterization of photocatalytic porcelain gres tiles are reported, as well as specific tests, in gas phase, to verify the effective photocatalytic efficiency of the samples. A comparison is initially reported between the photoactivity in the photodegradation of $\mathrm{NO}_{x}$ in gas phase of a pure commercial powdered nano$\mathrm{TiO}_{2}$ (AEROXIDE $\mathrm{TiO}_{2}$ P25 by Evonik, P25 referred in the following) and the commercial powdered micro- $\mathrm{TiO}_{2}$ (1077 by Kronos) used as starting material in the present tiles preparation. A specific session of the present paper will be also devoted to the discussion about the experimental setup to employ when tiles have to be investigated for the $\mathrm{NO}_{x}$ photodegradation in air with a plug-flow reactor built following the ISO 22197-1 rule [4].

\section{Experimental}

2.1. Preparation. Industrial porcelain gres tiles are manufactured under high pressure by dry-pressing fine processed ceramic raw materials with large proportions of quartz, feldspar, and other fluxes and finally fired at high temperatures $\left(1200-1300^{\circ} \mathrm{C}\right)$ in a kiln.

Photoactive porcelain gres tiles by GranitiFiandre S.p.A were subsequently covered at the surface with a mixture of pure anatase micro- $\mathrm{TiO}_{2}$ (1077 by Kronos) and a commercial $\mathrm{SiO}_{2}$-based compound. To ensure the requested product stability, at the end of the preparation procedure tiles were treated at high temperature $\left(\min 680^{\circ} \mathrm{C}\right.$ ) for $80 \mathrm{~min}$ and then brushed to remove the powder present at the sample surface and not completely stuck (samples name: Orosei Active). For the sake of comparison, samples were also prepared with the same procedure but without adding the photoactive oxide into the $\mathrm{SiO}_{2}$-based compound (Orosei).

2.2. Characterization. Specific surface area (SA) of powdered samples has been determined by conventional $\mathrm{N}_{2}$ absorption at $77 \mathrm{~K}$ (BET method) using a Sorptometer 1042 instrument (Costech). Before the analysis, the samples have been heated at $100^{\circ} \mathrm{C}$ for $12 \mathrm{~h}$ and then pretreated at $200^{\circ} \mathrm{C}$ in a nitrogen flow.

HR-TEM images were obtained by means of a JEOL 3010-UHR instrument (acceleration potential: $300 \mathrm{kV}$; LaB6 filament) equipped with an Oxford INCA X-ray energy dispersive spectrometer (XEDS) with a Pentafet $\mathrm{Si}(\mathrm{Li})$ detector. Samples were "dry" dispersed on lacey carbon Cu grids.

X-ray powder diffraction (XRD) patterns have been taken with a computerized Philips PW1710 diffractometer using the $\mathrm{CuK} \alpha$ radiation, operating at $40 \mathrm{kV}$ and $20 \mathrm{~mA}$, step scan $1 \mathrm{~min}^{-1}$, and $1 \mathrm{~s}$ counting time in the $2-40^{\circ}$ range at room temperature.

XPS measurements were performed in an M-Probe Instrument (SSI) equipped with a monochromatic $\mathrm{Al} \mathrm{K}{ }_{\alpha}$ source $(1486.6 \mathrm{eV})$ with a spot size of $200 \times 750 \mu \mathrm{m}$ and a pass energy of $25 \mathrm{eV}$, providing a resolution for $0.74 \mathrm{eV}$. The energy scale was calibrated with reference to the $4 \mathrm{f}_{7 / 2}$ level of a freshly evaporated gold sample, at $84.00 \pm 0.1 \mathrm{eV}$, and with reference to the $2 \mathrm{p}_{3 / 2}$ and $3 \mathrm{~s}$ levels of copper at $932.47 \pm 0.1$ and $122.39 \pm 0.15 \mathrm{eV}$, respectively. With a monochromatic source, an electron flood gun was used to compensate the buildup of positive charge on the insulator samples during the analyses: a value of $10 \mathrm{eV}$ was selected to perform measurements on these samples.

The surface wettability was evaluated by static contact angle (CA) measurements performed with an OCA20 instrument (DataPhysics Co., Germany) equipped with a CCD camera and a $500 \mu \mathrm{L}$-Hamilton syringe to dispense liquid droplets. Measurements were made at room temperature $\left(\sim 22^{\circ} \mathrm{C}\right)$ by means of the sessile drop technique and were replicated at least 15 times on each sample. Ultrapure water (HPLC grade, Sigma-Aldrich) was used as probe liquids and the volume of drop was fixed at $2 \mu \mathrm{L}$. The Young-Laplace fitting method was used in the calculation of static contact angles for all measurements giving an experimental error of $\pm 5 \%$ due to the surface roughness of the samples $[5,6]$ that was experimentally determined by a laser profilometry (3D laser profilometer, UBM Microfocus Compact, NanoFocus AG, Germany) with vertical and lateral resolution of $10 \mathrm{~nm}$. The parameters used during measurements follow the standard DIN 4768 and were adopted a transverse line measurement of $17.5 \mathrm{~mm}$ and a density of 150 dots per $\mathrm{mm}$.

2.3. Photocatalytic Tests. Pure commercial powders (P25 and 1007) were tested towards the photodegradation of $\mathrm{NO}_{x}$ in air in a static experimental setup already described in $[7,8]$ under the following conditions: $\mathrm{RH}: 50 \%, 10 \mathrm{Wm}^{-2}$, $V_{\text {reactor }}=20 \mathrm{~L}$, with a $\mathrm{NO}_{x}$ starting value of $1000 \mathrm{ppb}$. Immobilized particulate $\mathrm{TiO}_{2}$ layers (ca. $0.05 \mathrm{~g}$ ) were prepared on glass sheets by deposition from a suspension of the oxide in isopropanol [9]. 
Pure 1077 and P25 powders (always immobilized on a glass sheet) and tiles were tested towards the same reaction but in flowing conditions using a plug-flow reactor built following strictly the ISO 22197-1 rule [4] with an effective volume of $0.025 \mathrm{~L}$. Experimental conditions were maintained as follows: RH: $40 \%, 20 \mathrm{Wm}^{-2},\left[\mathrm{NO}_{x}\right]_{\text {inlet }} 500 \mathrm{ppb}$, and 180 , $32.4,9$, and $4.2 \mathrm{~L} \mathrm{~h}^{-1}$ total flow, respectively.

A chemiluminescent analyzer (Teledyne Instruments M200E) was used to check the final conversion of the pollutant in both batch and plug-flow reactor setpus.

The reactor configuration under flowing conditions was also modeled by digital simulations carried out using COMSOL Multiphysics 4.0a coupling the laminar flow (experimentally verified) with the transport of diluted species physics in a $3 \mathrm{D}$ space with each geometry resembling the relevant reactor dimensions and considering steadystate conditions. Each simulation was carried out using the following values: $C_{0 \text {,in }}=2.04 \times 10^{-5} \mathrm{~mol} \mathrm{~m}^{-3}$ (equivalent to $500 \mathrm{ppb}$ of $\mathrm{NO}_{x}$ ); $\rho=1.165 \mathrm{~kg} \mathrm{~m}^{-3}$ (air density at $30^{\circ} \mathrm{C}$ ); $\mu=1.86 \times 10^{-5} \mathrm{Pas}$ (air dynamic viscosity at $30^{\circ} \mathrm{C}$ ); $D=$ $1.9 \times 10^{-5} \mathrm{~m}^{2} \mathrm{~s}^{-1}$ (diffusion coefficient of $\mathrm{NO}_{2}$ in air [10]).

Simulations were performed considering six different inlet fluxes: $V_{\text {in }}\left(4.2,9,20,32.4,100\right.$, and $\left.180 \mathrm{~L} \mathrm{~h}^{-1}\right)$ and three different apparent reaction rate values, two of them calculated on the basis of the experimental results obtained using two catalysts studied in this work (Orosei Active and pure 1077, resp.) at $32.4 \mathrm{~L} \mathrm{~h}^{-1}$ and the third calculated at $180 \mathrm{Lh}^{-1}$. A first-order kinetic was considered for the reaction, as usual in photocatalysis with reactants such as $\mathrm{NO}_{x}$ at sub-ppm level $[11,12]$. The apparent kinetic constant was determined by performing simulations varying $k_{\text {app }}$ until the $\mathrm{NO}_{x}$ conversion resembled the experimental one. After this, $k_{\text {app }}$ was used for the remaining $V_{\text {in }}$ values.

The reaction on the catalytic surface was simulated by imposing an outlet flux of matter through the central surface that corresponds to the photoactive tile. The flux, expressed in $\mathrm{mol} \mathrm{m}^{-2} \mathrm{~s}^{-1}$, is set as equal to $k_{\mathrm{app}} \cdot\left[\mathrm{NO}_{x}\right]_{\mathrm{s}}$ (the subscript indicates that $\left[\mathrm{NO}_{x}\right]$ at the catalyst surface is considered). It follows that the rate constant values found in this work do not coincide with the real values of the chemical rate constant for the considered reaction. The following values were obtained: $k_{\text {app }}=2.3 \times 10^{-3} \mathrm{~m} \mathrm{~s}^{-1}$ (Orosei Active) or $4 \times 10^{-3} \mathrm{~m} \mathrm{~s}^{-1}$ (pure 1077) at $32.4 \mathrm{~L} \mathrm{~h}^{-1}$ and $k_{\text {app }}=1.0 \times$ $10^{-4} \mathrm{~m} \mathrm{~s}^{-1}$ for both Orosei Active and 1077 at $180 \mathrm{~L} \mathrm{~h}^{-1}$.

\section{Results and Discussion}

3.1. Sample Characterization. A feature comparison of both pure $\mathrm{TiO}_{2}$ and $\mathrm{TiO}_{2}+\mathrm{SiO}_{2}$-based compound after the calcination treatment at $680^{\circ} \mathrm{C}$ shows the decrease of the surface area from 11.0 to $2.6 \mathrm{~m}^{2} \mathrm{~g}^{-1}$ (BET measurements). From the surface point of view, XPS analysis reveals the classical Ti2p doublet at $458.6 \mathrm{ev}\left(\mathrm{Ti} 2 \mathrm{p}_{3 / 2}\right)$ attributed to $\mathrm{Ti}^{4+}$ with a $\mathrm{Ti} / \mathrm{Si}$ ratio of 0.20 .

The formulation with the $\mathrm{SiO}_{2}$-based compounds and the following calcination step lead to a decrease of the surface area but preservation of the pure anatase form verified by XRD measurements [13]. As reported by Anderson and Bard
[14], the presence of $\mathrm{SiO}_{2}$, together with $\mathrm{TiO}_{2}$, enhances the formation of hydroxyl radical ${ }^{\bullet} \mathrm{OH}$, which would be achieved via strong Brønsted acid sites at the $\mathrm{TiO}_{2} / \mathrm{SiO}_{2}$ interface region. Such incorporation inhibits the crystal growth of $\mathrm{TiO}_{2}$ allowing the preservation of the anatase structure at high temperature [15].

In order to investigate the morphological features of the various samples, HR-TEM technique has been resorted to. $\mathrm{P} 25$ nano-sized $\mathrm{TiO}_{2}$ has been also investigated, and its images are reported in Figures 1(a) and 1(b): it can be observed that the P25 material is made up of highly crystalline closely packed particles, as either thickness or Moirè's fringe patterns are evident (right-hand image) [16] with rather smooth edges. The average particle size is in agreement with literature data [17], that is, $20-50 \mathrm{~nm}$ range. The detailed inspection of the spacings among the interference fringes $(d=0.357 \mathrm{~nm})$ indicates that the most frequently exposed planes belong to the $\mathrm{TiO}_{2}(101)$ anatase polymorph [18]. If both particle size and ultimate morphology of the plain Kronos $\mathrm{TiO}_{2}$ sample (see Figures 1(c) and 1(d)) are compared to the P25 features, it can be evidenced that (i) particles are still packed, but to a limited extent if compared to the P25, and the edges of the particles are quite smooth; (ii) the size of the crystallites has enormously enlarged, as in the present case the average size varies in the 100$250 \mathrm{~nm}$ range; (iii) if we inspect the distances among the fringes, it is evident that the spacings $(d=0.357 \mathrm{~nm})$ are still ascribable to the anatase polymorph. When the presence of the $\mathrm{SiO}_{2}$-based compound is considered, it can be stated that, roughly morphologically speaking, the main features of the $\mathrm{TiO}_{2}$ particles are maintained: see, for instance, Figures $1(\mathrm{e})$ and 1(f), in which the large dimensions of the particles are evident (50-200 $\mathrm{nm}$ range), beside rather smooth edges. Nevertheless, some peculiarities have to be mentioned: in particular, the presence of the $\mathrm{SiO}_{2}$-based compound is evident (see either the inset in Figure 1(e) or Figure 1(f)), in the form of either small protruding crystalline particles or an amorphous coating covering the $\mathrm{TiO}_{2}$ particles. In any case, the very thin nature of these particles and/or coating allows to inspect the fringe patterns located below, confirming that the spacings among the fringes are still ascribable to the anatase $\mathrm{TiO}_{2}$ polymorph.

Wettability measurements were performed on 15 different areas of both Orosei and Orosei Active (Figures 2(a) and 2(b), resp.). Drop shapes are dramatically different enhancing a completely different surface. Orosei sample shows a mean contact angle value of $78.2^{\circ}$, while Orosei Active shows very hydrophilic surface features with an average angle of $23.0^{\circ}$. This very low value can be explained by the super-hydrophilic property of $\mathrm{TiO}_{2}$ photocatalyst as already observed by other authors [19]. In particular the copresence of $\mathrm{TiO}_{2}$ and $\mathrm{SiO}_{2}$ can lead to a modification of the angle value depending on the $\mathrm{TiO}_{2} / \mathrm{SiO}_{2}$ ratio [20] with values in the range of $20-25^{\circ}$ with a $\mathrm{SiO}_{2}$ content at $70-80 \%$ (molar basis), in agreement with the XPS Ti/Si ratio obtained on Orosei Active.

Samples roughness, measured as root mean squared $\left(R_{q}\right)$, was $19.354 \mu \mathrm{m}$ and $18.860 \mu \mathrm{m}$ for Orosei Active and Orosei (Ti-free), respectively. 


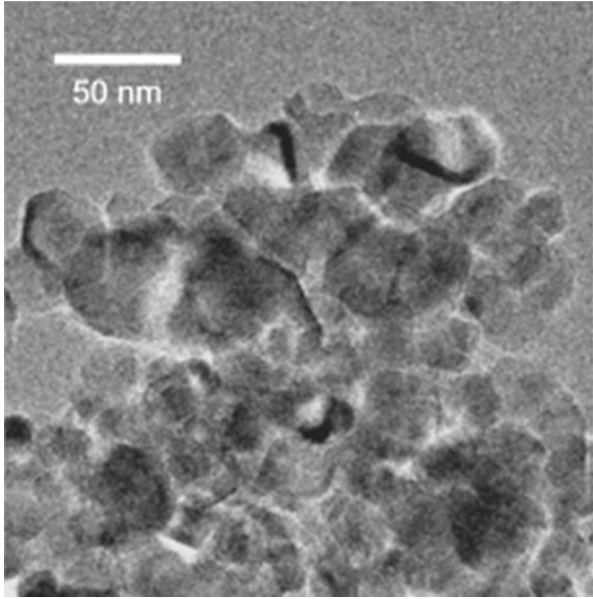

(a)

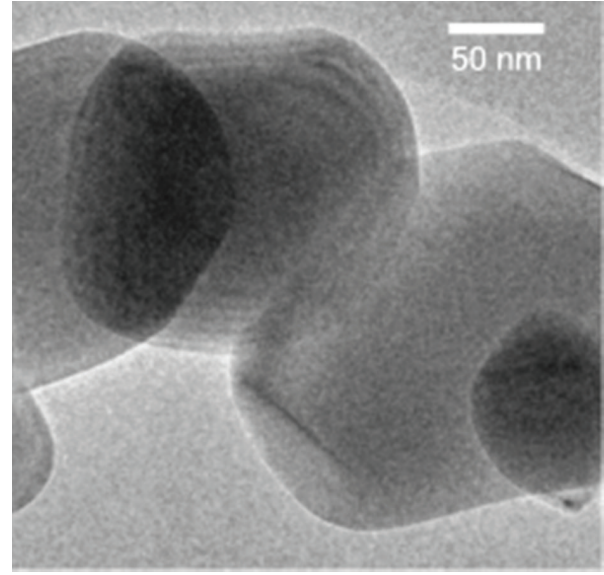

(c)

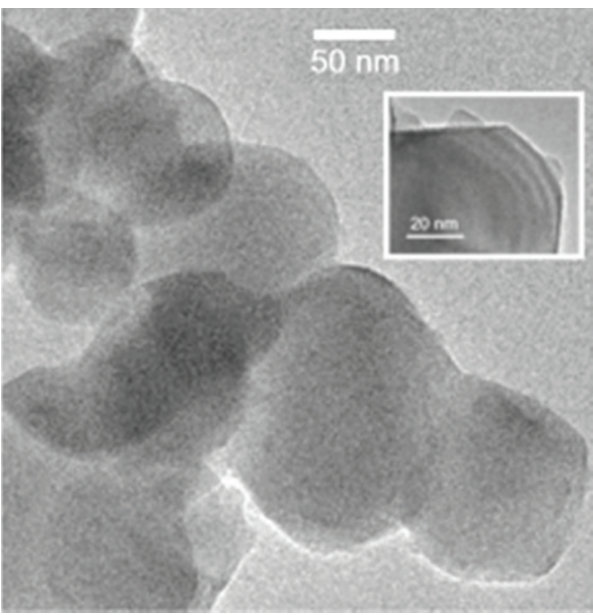

(e)

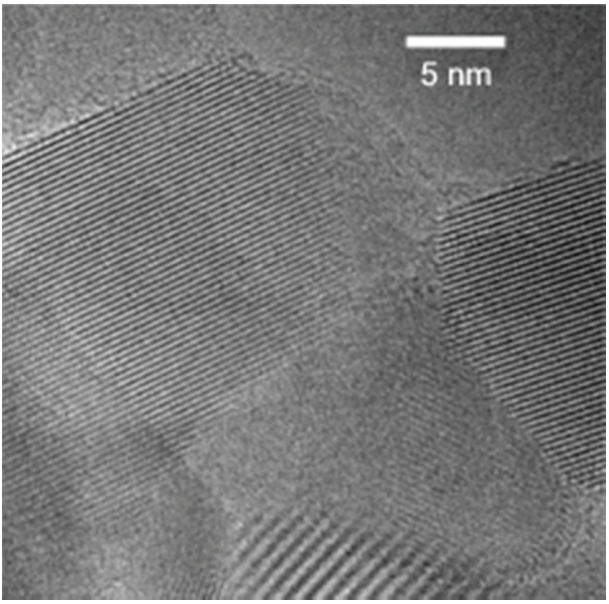

(b)

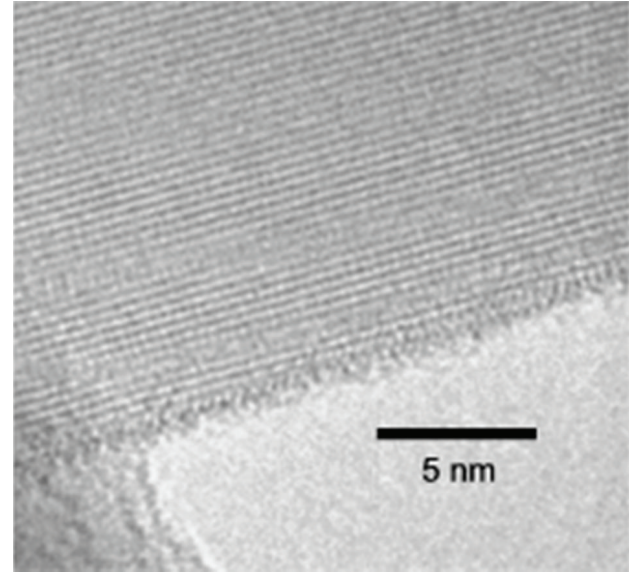

(d)

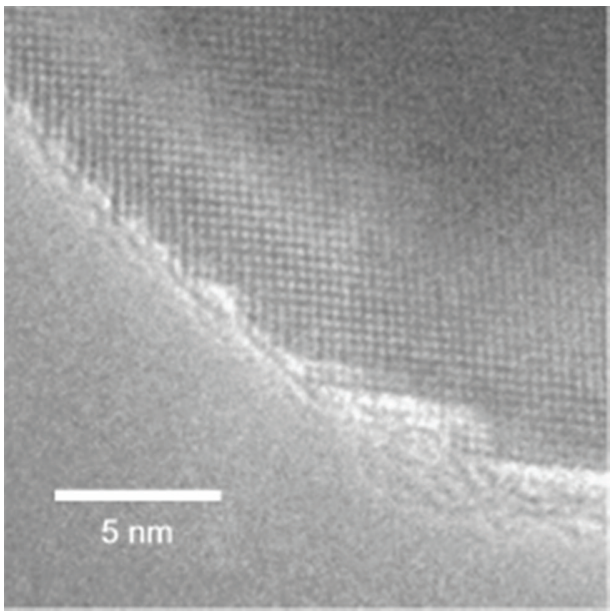

(f)

Figure 1: HR-TEM images of the various $\mathrm{TiO}_{2}$ materials. (a) and (b): P25. (c) and (d): 1077. (e) and (f): Orosei Active. (a), (c), and (e) refer to low magnification, here as (b), (d), and (f) to high magnification.

\subsection{Photocatalytic Tests}

3.2.1. Batch Reactor. Figure 3 reports the rate of $\mathrm{NO}_{x}$ degradation for $\mathrm{P} 25$ and 1077. The $\mathrm{NO}_{x}$ concentration is the sum of the $\mathrm{NO}$ and $\mathrm{NO}_{2}$ concentrations; the general mechanism of $\mathrm{NO}_{x}$ oxidation by photocatalysts implies the oxidation of the nitric monoxide to nitric acid or nitrous by active oxygen species produced on the $\mathrm{TiO}_{2}$ surface [21].

P25 is, as expected, more efficient than 1077 and it reaches a full $\mathrm{NO}_{x}$ degradation $(1000 \mathrm{ppb})$ in about $2 \mathrm{~h}$. 


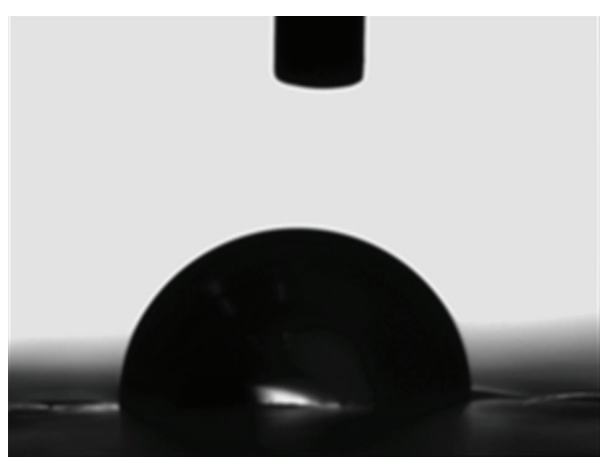

(a)

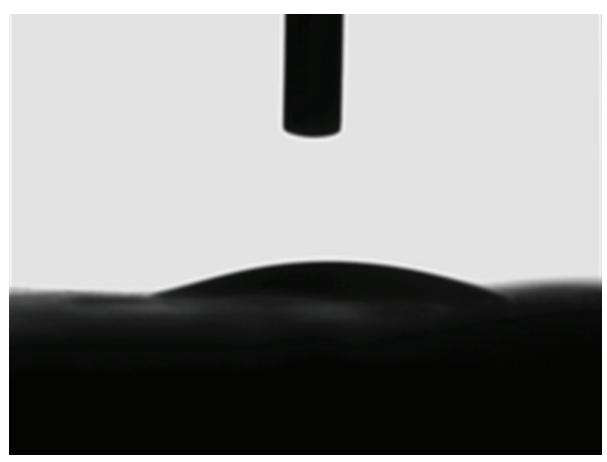

(b)

Figure 2: Contact angle: (a) Orosei; (b) Orosei Active tiles.

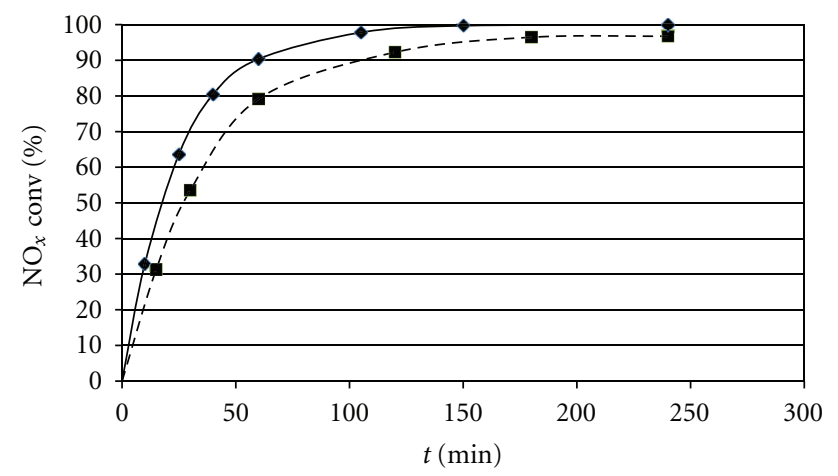

Figure 3: Comparison between P25 ( ) and $1077(\boldsymbol{\square})$ in the $\mathrm{NO}_{x}$ photodegradation in a batch reactor.

On the contrary, 1077 never reaches a complete $\mathrm{NO}_{x}$ degradation within the $6 \mathrm{~h}$ of test but, notwithstanding the larger crystallite size and the lower surface area, shows a $90 \%$ conversion after $100 \mathrm{~min}$ of irradiation.

3.2.2. Plug-Flow Reactor. ISO 22197-1 rule provides for very sharp experimental conditions such as an inlet $\mathrm{NO}_{x}$ concentration of $1000 \mathrm{ppb}$ coupled with a low irradiation power $\left(10 \mathrm{Wm}^{-2}\right)$ and mainly with a very strong flow at $180 \mathrm{~L} \mathrm{~h}^{-1}$. These conditions are too extreme for our samples being vitrified at their surface and having no porosity.

For these reasons, the operating conditions have been softened cutting the inlet concentration by half ( $500 \mathrm{ppb})$, doubling the power irradiation $\left(20 \mathrm{Wm}^{-2}\right)$, and investigating the role of the flow per hour on the final $\mathrm{NO}_{x}$ conversion. To check to have maintained the correct fluid dynamic conditions, the Reynolds number was calculated:

$$
\mathrm{Re}=\frac{\rho U D_{e}}{\mu},
$$

where $U$ is the is the velocity of the fluid $\left(\mathrm{m} \mathrm{s}^{-1}\right), \mu$ is the dynamic viscosity of the fluid $\left(\mathrm{kg} \mathrm{m}^{-1} \mathrm{~s}^{-1}\right), \rho$ is the density of the fluid $\left(\mathrm{kg} \mathrm{m}^{-3}\right)$, and $D_{e}$ is the hydraulic diameter of the pipe $(\mathrm{m})$, defined as 4 times the cross-sectional area (of the fluid), divided by the wetted perimeter. The wetted perimeter for a channel is the total perimeter of all channel walls that are in contact with the flow. In all chosen flows of the present paper, the laminar flow is confirmed (Table 1, second column).

On the contrary, the modification of the flow per hour leads to the an evident change of the contact times that is the time the pollutant can stay "in contact" with the catalyst surface. As expected, increasing the contact time, the final conversion proportionally increases. This result is very evident for Orosei Active that shows a conversion varying from $1.3 \%$ to $82.0 \%$ at $180 \mathrm{~L} \mathrm{~h}^{-1}$ and $4.2 \mathrm{~L} \mathrm{~h}^{-1}$, respectively (Table 1, seventh column). On the contrary, a sample of pure 1077, prepared on purpose on a glass sheet following the same procedure used for the batch setup, shows higher $\mathrm{NO}_{x}$ conversion, but flattened towards the same value (ca. 90\%).

This fact is very interesting and was observed also performing the test on a three-layer of P25. In this case a value of ca. $90 \%$ was observed at both 32.4 and $9 \mathrm{~L} \mathrm{~h}^{-1}$ too, and a complete degradation (100\%) was never present in our operative conditions as some fluid dynamics problems could exist inside the reactor configuration and part of the gas stream could pass undisturbed through the reactor. Moreover, the difference in the photocatalytic efficiency between P25 and 1077 evidenced by the tests performed in the batch reactor seems to be completely invalidated with this kind of reactor configuration.

The higher $\mathrm{NO}_{x}$ conversion of pure 1077 than Orosei Active was fully expected as the number of surface of active sites on the tile surface is not comparable to a film of pure $\mathrm{TiO}_{2}$ on a glass sheet. For this reason, the obtained $82 \%$ conversion at $4.2 \mathrm{~L} \mathrm{~h}^{-1}$ flow can be considered a very good value.

3.3. Digital Simulations. Figure 4 reports a $x z$ cross-section of the gas stream $3 \mathrm{D}$ fluid dynamics digital simulation in the two extreme flow rates: 180 and $4.2 \mathrm{~L} \mathrm{~h}^{-1}$. In more detail, the figure reports the local gas linear speed in the inlet side of the photoreactor. It is evident that the linear velocity of the gas stream is strongly influenced by the inlet flow rate: at $4.2 \mathrm{~L} \mathrm{~h}^{-1}$ the gas stream follows a natural path from the inlet to the channel containing the photoactive material, while at $180 \mathrm{~L} \mathrm{~h}^{-1}$ the inlet speed makes the gas to hit the wall in front of the inlet. 
TABle 1: Data from continuous reactor and Comsol simulations $\left(\mathrm{NO}_{x} 500 \mathrm{ppb}, 20 \mathrm{Wm}^{-2}\right.$, sample size $0.005 \mathrm{~cm}^{2}, \mathrm{RH}: 40 \%$, run time: $3 \mathrm{~h}$. For the Comsol simulation: laminar flow).

\begin{tabular}{lccccccc}
\hline $\begin{array}{l}\text { Flow } \\
\left(\mathrm{L} \mathrm{h}^{-1}\right)\end{array}$ & Reynold's number & $\begin{array}{c}\text { Space velocity } \\
\left(\mathrm{h}^{-1}\right)\end{array}$ & $\begin{array}{c}\text { Contact time } \\
(\mathrm{s})\end{array}$ & $\begin{array}{c}1077 \mathrm{NO}_{x} \text { conversion (\%) } \\
\text { Experimental } \\
\text { data }\end{array}$ & $\begin{array}{c}\text { Orosei Active } \mathrm{NO}_{x} \text { conversion }(\%) \\
\text { simulation }\end{array}$ & $\begin{array}{c}\text { Experimental } \\
\text { COMSOL } \\
\text { data }\end{array}$ \\
\hline 180.0 & 112 & 7200 & 0.5 & 5.0 & 36.8 & 1.3 & 25.6 \\
32.4 & 20 & 1296 & 2.8 & 89.1 & 87.5 & 74.2 & 74.9 \\
9.0 & 5.6 & 360 & 10.0 & 90.0 & 99.8 & 72.6 & 98.8 \\
4.2 & 2.5 & 168 & 21.4 & 90.1 & 100.0 & 82.0 & 100.0 \\
\hline
\end{tabular}

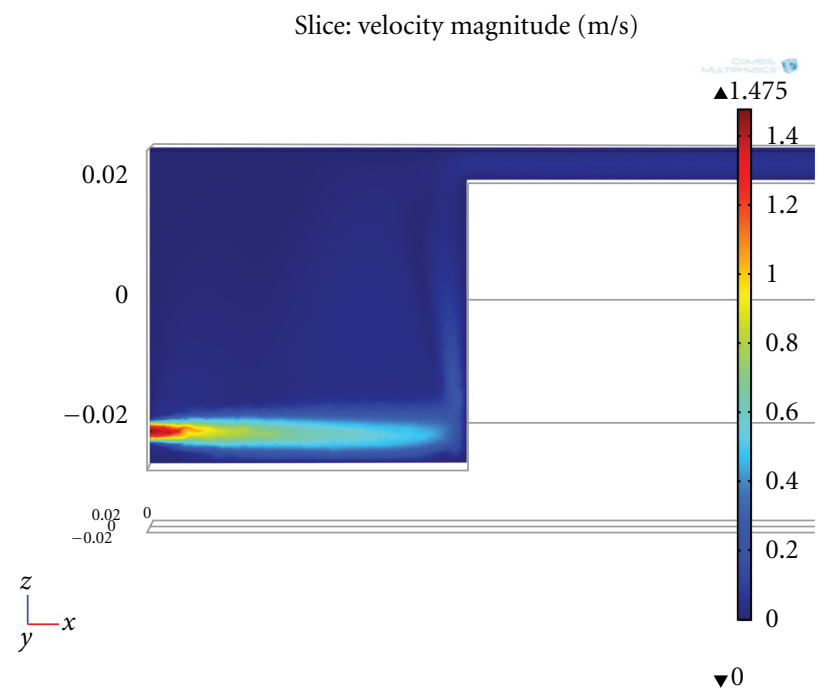

(a) $V_{\text {in }}=32.4 \mathrm{Lh}^{-1}$
Slice: velocity magnitude $(\mathrm{m} / \mathrm{s})$

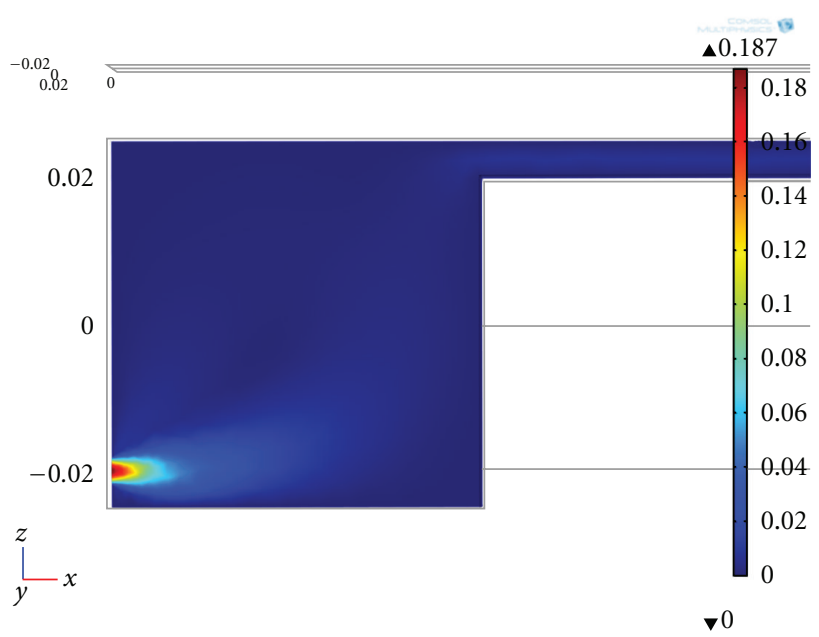

(b) $V_{\text {in }}=4.2 \mathrm{Lh}^{-1}$

Figure 4: $x y$ cross-sections of simulated fluid dynamic under steady-state conditions of the reactor used for the photocatalytic test (flowing conditions). (a) $V_{\text {in }}=32.4 \mathrm{Lh}^{-1}$, (b) $V_{\text {in }}=4.2 \mathrm{~L} \mathrm{~h}^{-1}$. The cross-section follows the longitudinal symmetry and is focused on the inlet gas chamber and a portion of the channel containing the photoactive tile.

Notwithstanding that this effect might generate some turbulence in the inlet chamber (not included in the present simulation), the fluid speed profile inside the channel containing the photoactive material remains homogeneous through the channel length. In both cases, in the channel containing the photoactive material, the gas follows speed profile typical of laminar flows.

Figure 5 represents the $x z$ cross-section of the simulated $\mathrm{NO}_{x}$ concentration profiles in the reactor volume under steady-state conditions. Note that the inlet is on the left side of the reactor (i.e., the same side considered in Figure 4), while the outlet is on the right. The color code represents in this case the concentration of $\mathrm{NO}_{x}$ in the air stream, expressed in $\mathrm{mol} \mathrm{m}^{-3}$ (500 ppb corresponds to $2.04 \times$ $10^{-5} \mathrm{~mol} \mathrm{~m}^{-3}$ ).

It is evident that, as expected, the concentration gradient is located at the reactor center, in correspondence to the photoactive tile. This is better represented in the two insets, $\mathrm{a}$ (in which the $3 \mathrm{D}$ space is transparent) and $\mathrm{b}$ ( $x z$ crosssection). In particular, inset $b$ suggests the formation of a concentration gradient generated by the consumption of $\mathrm{NO}_{x}$ at the photoactive surface. The gradient is at the origin of mass transport, that, at the lowest flow rate values, might become the rate determining step of the whole process, just before the maximum conversion $(100 \%)$ is reached; see the simulated points (Figure 6) and values in Table 1.

This is even more evident considering the experimental and simulated percentage $\mathrm{NO}_{x}$ conversion values in dependence on the flow rate, reported in Figure 6 . In the case of simulated results, which include the data at $20 \mathrm{Lh}^{-1}$ and $100 \mathrm{Lh}^{-1}$ as well as a set of data corresponding to $k_{\mathrm{app}}=1$ $\times 10^{-4} \mathrm{~s}^{-1}$ it is evident that the trend follows the expected exponential decay predicted by a first-order kinetics:

$$
\begin{aligned}
\mathrm{NO}_{x} \text { conversion } & =\frac{\left(\left[\mathrm{NO}_{x}\right]_{\text {inlet }}-\left[\mathrm{NO}_{x}\right]_{\text {outlet }}\right)}{\left[\mathrm{NO}_{x}\right]_{\text {inlet }}} \cdot 100 \\
& =100 \cdot\left(1-e^{-k t}\right) .
\end{aligned}
$$

In fact, the flow rate is inversely proportional to the contact time and thus to the reaction time, $t$. At the lowest flow rates (highest reaction times) a limiting-value results are reached, as indicated in Figure 6 by the colored ovals. These limiting values are $100 \%$ for the simulated data and about $90 \%$ for the experimental. This unexpected discrepancy can 


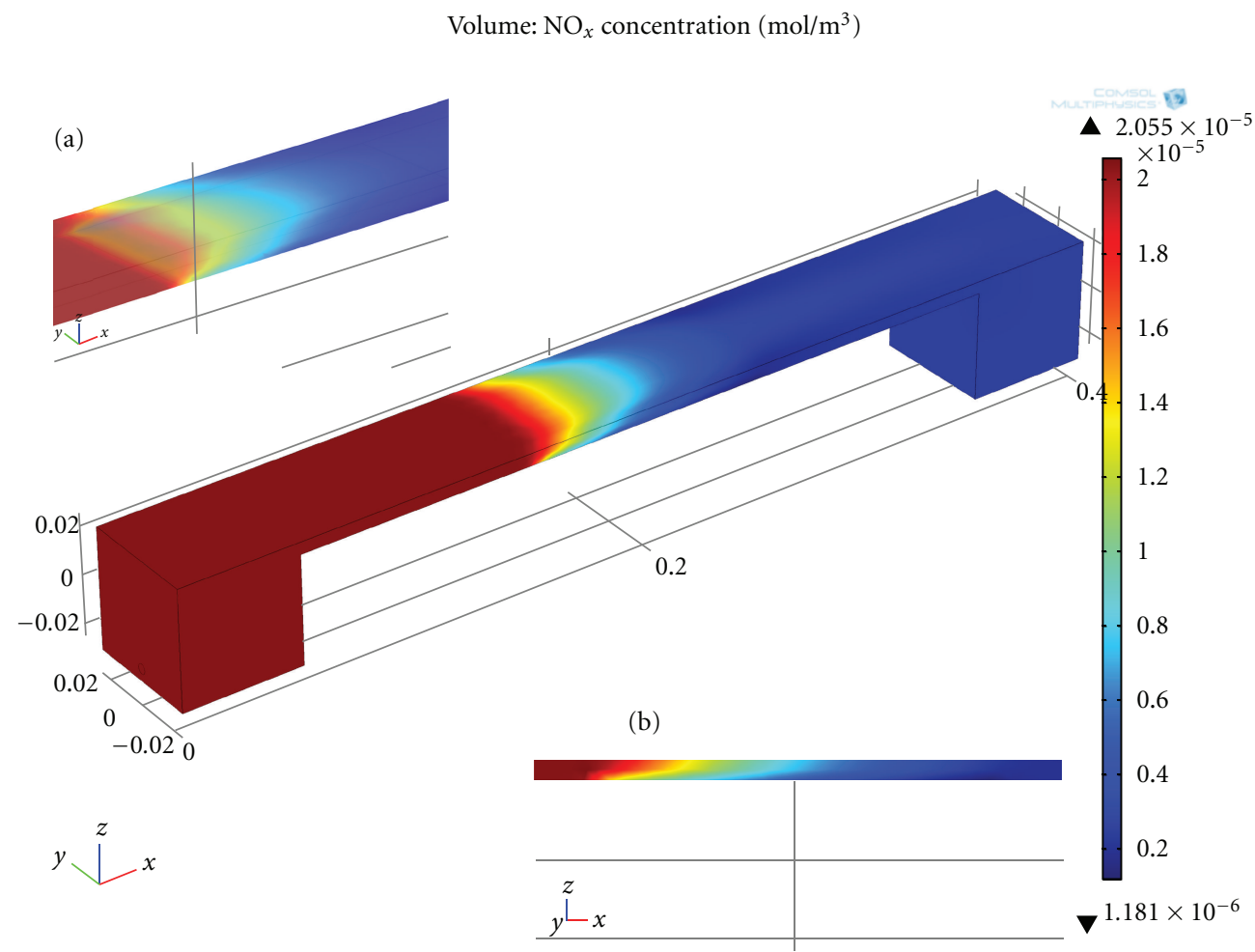

FIGURE 5: $\mathrm{NO}_{x}$ local concentration in the reactor volume, expressed in $\mathrm{mol} \mathrm{m}^{-3}\left(k_{\text {app }}=4 \times 10^{-3} \mathrm{~m} \mathrm{~s}^{-1}, 32.4 \mathrm{~L} \mathrm{~h}^{-1}\right)$. Inset (a), zoom on the photoactive tile; inset (b), $x z$ cross-section of the photoactive tile.

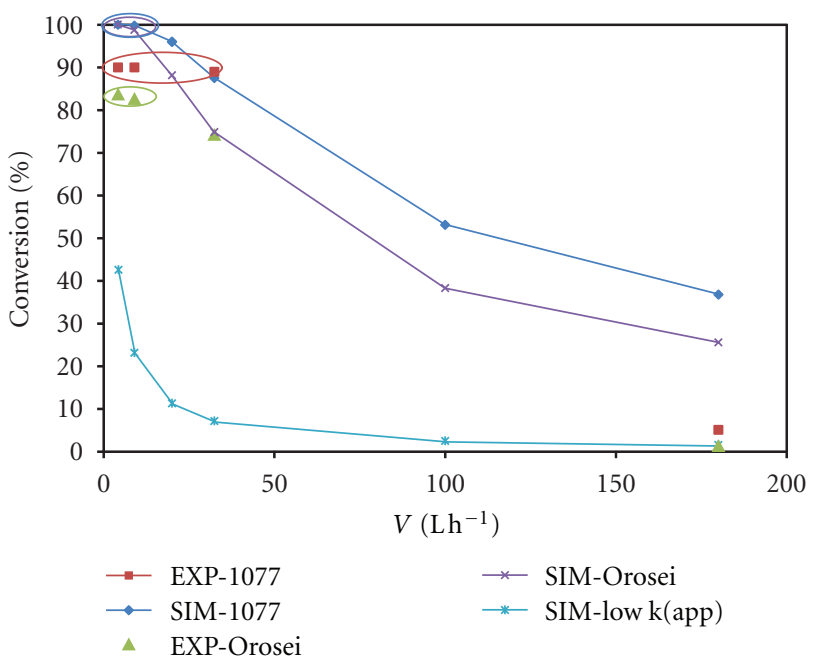

FIgURe 6: Experimental (EXP) and simulated (SIM) percentage conversion in dependence on the flow rate, as reported in Table 1 relevant to the two samples considered in the flowing condition experiments (1077 and Orosei active) or the relevant simulated apparent kinetic constants $\left(4 \times 10^{-3}\right.$ and $2.3 \times 10^{-3} \mathrm{~m} \mathrm{~s}^{-1}$, respectively. The light blue curve corresponds to the simulated data adopting a lower apparent kinetic constant, $1 \times 10^{-4} \mathrm{~m} \mathrm{~s}^{-1}$.

be explained considering the existence of preferential gas paths on the tiles sides (uncovered by the catalyst) that lead to the presence of unreacted $\mathrm{NO}_{x}$ at the reactor outlet.
The figures also evidence that the only common points between simulated and experimental data are those obtained 32.4 $\mathrm{Lh}^{-1}$, that is, the conditions at which the kinetic constants used in the simulations have been determined. In other words, this means that also the experimental results obtained at high flow rates do not find any correspondence with the simulated data. This might be explained by the formation, in the real reactor, of turbulence (likely in the inlet chamber) that can actually change the fluid dynamics of the whole system due to the reactor geometry.

\section{Conclusions}

Microsized $\mathrm{TiO}_{2}$ can be really used as a valid choice for antipollutant photocatalytic processes avoiding the intrinsic risk due to the nanometric dimension. $\mathrm{TiO}_{2}$ larger size compared to more traditional nano-sized crystallites allows to reach fully comparable results in the photodegradation of $\mathrm{NO}_{x}$, reference molecule for outdoor air pollution.

Good photocatalytic efficiency was achieved by the pure commercial microsized powder in comparison to P25. Porcelain gres tiles prepared entrapping micro- $\mathrm{TiO}_{2}$ at the $\mathrm{SiO}_{2}$ surface also show a stable and reproducible photocatalytic activity towards the degradation of $\mathrm{NO}_{x}$ in air as expected by the surface feature results (surface wettability and $\mathrm{Ti}$ content).

Employed $\mathrm{NO}_{x}$ photoreactor was built following the ISO 22197-1 rule but the requested ISO experimental conditions, such as inlet $\mathrm{NO}_{x}$ concentration, low irradiation power, and 
high flow, are too extreme for our tiles samples being vitrified at their surface and having no porosity. For these reasons, the operating conditions have been softened and the role of the flow per hour on the final $\mathrm{NO}_{x}$ conversion was fully investigated.

The discrepancies between the experimental data and the simulated ones might be related to the presence of preferential gas paths in the test reactor and to the formation of turbulence (due to the reactor geometry) in the case of the highest flow rate values.

\section{Acknowledgment}

A. Minguzzi is grateful to Università degli Studi di Milano for fundings (PUR 2009) and for a post-doc fellowship.

\section{References}

[1] R. Casasola, J. M. Rincón, and M. Romero, "Glass-ceramic glazes for ceramic tiles: a review," Journal of Materials Science, vol. 47, no. 2, pp. 553-582, 2012.

[2] S. Singh and H. S. Nalwa, "Nanotechnology and health safety-toxicity and risk assessments of nanostructured materials on human health," Journal of Nanoscience and Nanotechnology, vol. 7, no. 9, pp. 3048-3070, 2007.

[3] B. Trouiller, R. Reliene, A. Westbrook, P. Solaimani, and R. H. Schiestl, "Titanium dioxide nanoparticles induce DNA damage and genetic instability in vivo in mice," Cancer Research, vol. 69, no. 22, pp. 8784-8789, 2009.

[4] "ISO 22197-1-test method for air-purification performance of semiconducting photocatalytic materials. Part1: removal of nitric oxide," http://www.iso.org/iso/home.html.

[5] J. Drelich and E. Chibowski, "Superhydrophilic and superwetting surfaces: definition and mechanisms of control," Langmuir, vol. 26, no. 24, pp. 18621-18623, 2010.

[6] T. Watanabe, S. Fukayama, M. Miyauchi, A. Fujishima, and K. Hashimoto, "Photocatalytic activity and photo-induced wettability conversion of $\mathrm{TiO}_{2}$ thin film prepared by sol-gel process on a soda-lime glass," Journal of Sol-Gel Science and Technology, vol. 19, no. 1-3, pp. 71-76, 2000.

[7] S. Ardizzone, C. L. Bianchi, G. Cappelletti, S. Gialanella, C. Pirola, and V. Ragaini, "Tailored anatase/brookite nanocrystalline $\mathrm{TiO}_{2}$. the optimal particle features for liquidand gasphase photocatalytic reactions," Journal of Physical Chemistry C, vol. 111, no. 35, pp. 13222-13231, 2007.

[8] C. Pirola, D. C. Boffito, S. Vitali, and C. L. Bianchi, "Photocatalytic coatings for building industry: study of 1 year of activity in the $\mathrm{NO}_{x}$ degradation," Journal of Coatings Technology and Research, vol. 9, no. 4, pp. 453-458, 2012.

[9] C. L. Bianchi, C. Pirola, E. Selli, and S. Biella, "Photocatalytic $\mathrm{NO}_{x}$ abatement: the role of the material supporting the $\mathrm{TiO}_{2}$ active layer," Journal of Hazardous Materials, vol. 211-212, pp. 203-207, 2012.

[10] N. H. Chen and D. F. Othmer, "New generalized equation for gas diffusion coefficient," Journal of Chemical and Engineering Data, vol. 7, no. 1, pp. 37-41, 1962.

[11] T. N. Obee and R. T. Brown, " $\mathrm{TiO}_{2}$ photocatalysis for indoor air applications: effects of humidity and trace contaminant levels on the oxidation rates of formaldehyde, toluene, and 1,3butadiene," Environmental Science and Technology, vol. 29, no. 5, pp. 1223-1231, 1995.
[12] D. T. Tomkins, W. A. Zeltner, B. J. Lawnicki, and M. A. Anderson, "Evaluation of Photocatalysis for Gas-Phase Air Cleaning Part 1: Process, Technical, and Sizing Considerations," ASHRAE Transactions, vol. 111, no. 2, p. 64, 2005.

[13] C. L. Bianchi, S. Gatto, C. Pirola, M. Scavini, S. Vitali, and V. Capucci, "Micro- $\mathrm{TiO}_{2}$ as a Starting Material for New Photocatalytic Tiles," Cement and Concrete Composites. In press.

[14] C. Anderson and A. J. Bard, "Improved photocatalytic activity and characterization of mixed $\mathrm{TiO}_{2} / \mathrm{SiO}_{2}$ and $\mathrm{TiO}_{2} / \mathrm{Al}_{2} \mathrm{O}_{3}$ materials," Journal of Physical Chemistry B, vol. 101, no. 14, pp. 2611-2616, 1997.

[15] T.-H. Xie and J. Lin, "Origin of photocatalytic deactivation of $\mathrm{TiO}_{2}$ film coated on ceramic substrate," Journal of Physical Chemistry C, vol. 111, no. 27, pp. 9968-9974, 2007.

[16] R. I. Bickley, T. Gonzalez-Carreno, J. S. Lees, L. Palmisano, and R. J. D. Tilley, "A structural investigation of titanium dioxide photocatalysts," Journal of Solid State Chemistry, vol. 92, no. 1, pp. 178-190, 1991.

[17] G. Cerrato, L. Marchese, and C. Morterra, "Structural and morphological modifications of sintering microcrystalline $\mathrm{TiO}_{2}$ : an XRD, HRTEM and FTIR study," Applied Surface Science, vol. 70-71, pp. 200-205, 1993.

[18] Anatase ICCD card File 21-1272.

[19] R. Wang, K. Hashimoto, A. Fujishima et al., "Light-induced amphiphilic surfaces," Nature, vol. 388, no. 6641, pp. 431-432, 1997.

[20] M. Machida, K. Norimoto, T. Watanabe, K. Hashimoto, and A. Fujishima, "Effect of $\mathrm{SiO}_{2}$ addition in super-hydrophilic property of $\mathrm{TiO}_{2}$ photocatalyst," Journal of Materials Science, vol. 34, no. 11, pp. 2569-2574, 1999.

[21] Y. H. Tseng, C. S. Kuo, C. H. Huang et al., "Visible-lightresponsive nano- $\mathrm{TiO}_{2}$ with mixed crystal lattice and its photocatalytic activity," Nanotechnology, vol. 17, no. 10, pp. 2490-2497, 2006. 

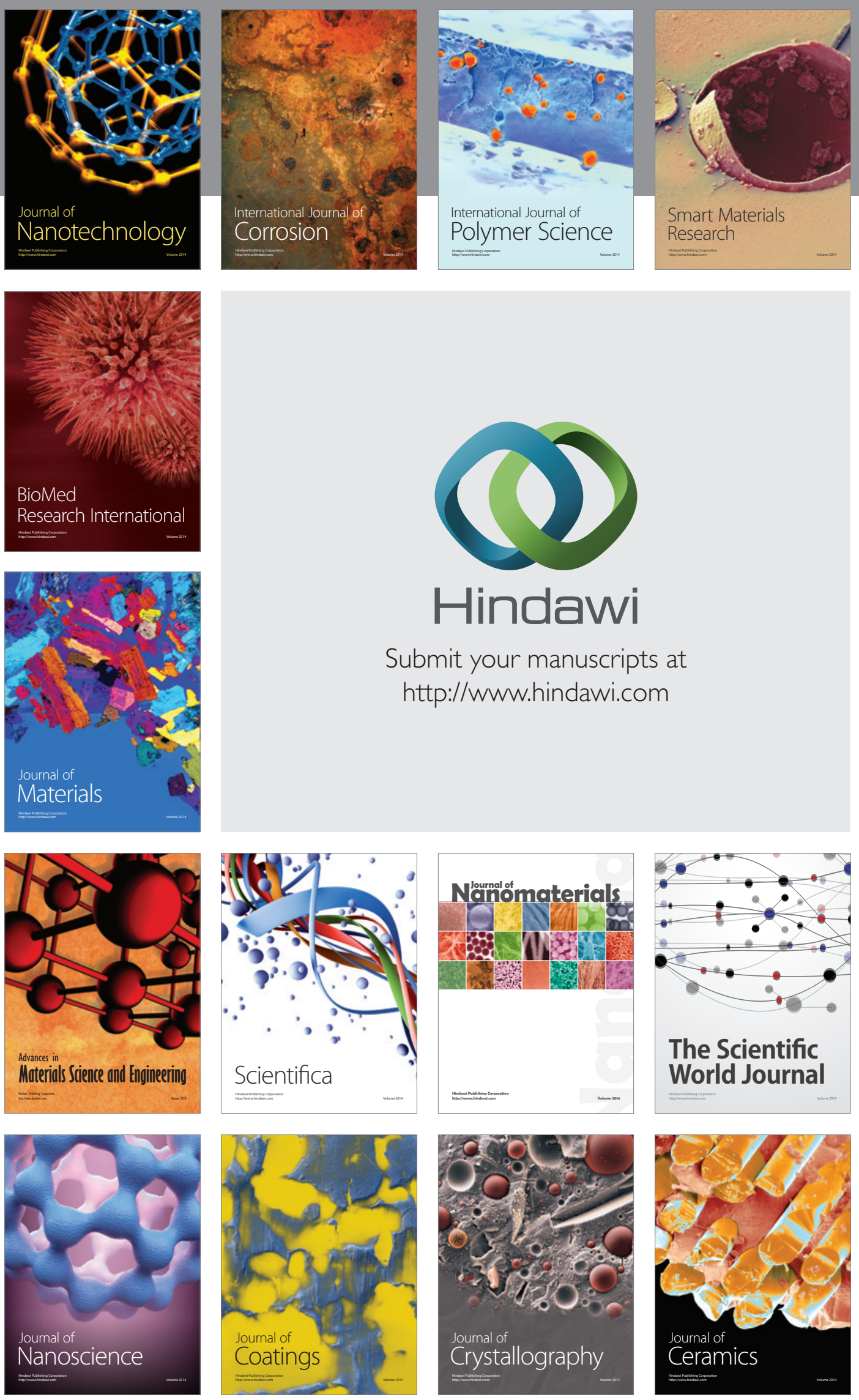

The Scientific World Journal

Submit your manuscripts at

http://www.hindawi.com

\section{World Journal}

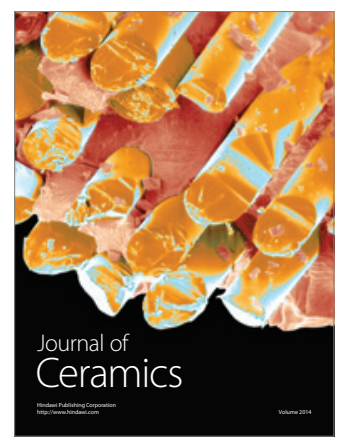

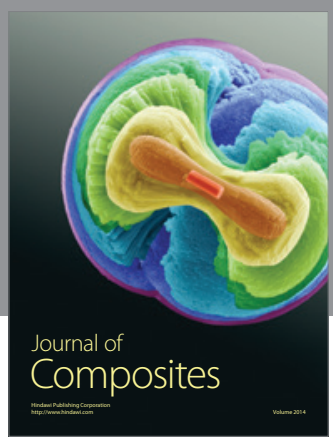
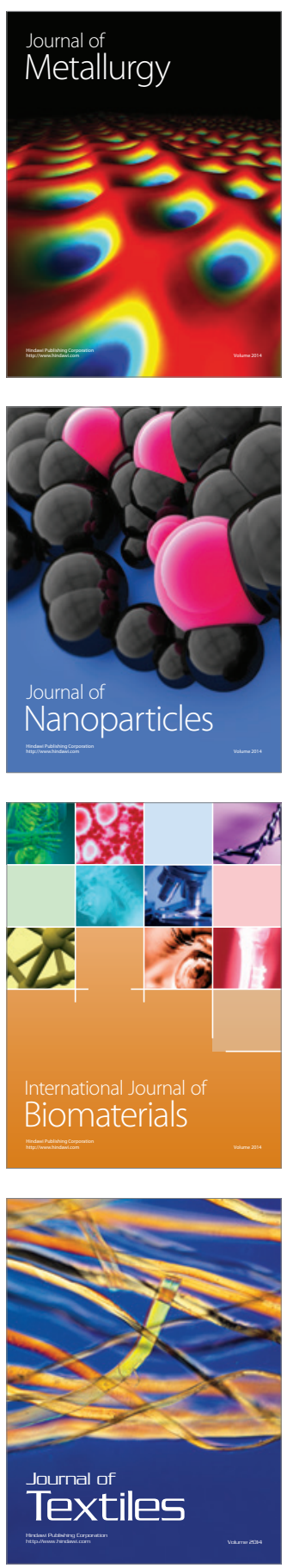